\title{
Vascular endothelial growth factor and receptor interaction is a prerequisite for murine hepatic fibrogenesis
}

\author{
H Yoshiii, S Kuriyama, J Yoshii, Y Ikenaka, R Noguchi, D J Hicklin, Y Wu, K Yanase, \\ T Namisaki, M Yamazaki, H Tsujinoue, H Imazu, T Masaki, H Fukui
}

Gut 2003;52:1347-1354

See end of article for authors' affiliations

\section{Correspondence to:} Dr H Yoshiji, Third Department of Internal Medicine, Nara Medical University, Shijo-cho 840, Kashihara, Nara 634-8522, Japan yoshijih@naramed-u.ac.jp

Accepted for publication 28 May 2003
Background: It has been shown that expression of the potent angiogenic factor, vascular endothelial growth factor (VEGF), and its receptors, flt-1 (VEGFR-1) and KDR/Flk-1 (VEGFR-2), increased during the development of liver fibrosis.

Aims: To elucidate the in vivo role of interaction between VEGF and its receptors in liver fibrogenesis. Methods: A model of $\mathrm{CCl}_{4}$ induced hepatic fibrosis was used to assess the role of VEGFR-1 and VEGFR-2 by means of specific neutralising monoclonal antibodies (R-1mAb and R-2mAb, respectively). $R-1 \mathrm{mAb}$ and $\mathrm{R}-2 \mathrm{mAb}$ were administered after two weeks of treatment with $\mathrm{CCl}_{4}$, and indices of fibrosis were assessed at eight weeks.

Results: Hepatic VEGF mRNA expression significantly increased during the development of liver fibrosis. Both R-1mAb and R-2mAb treatments significantly attenuated the development of fibrosis associated with suppression of neovascularisation in the liver. Hepatic hydroxyproline and serum fibrosis markers were also suppressed. Furthermore, the number of $\alpha$-smooth muscle actin positive cells and $\alpha 1$ (I)-procollagen mRNA expression were significantly suppressed by $R-1 \mathrm{mAb}$ and $\mathrm{R}-2 \mathrm{mAb}$ treatment. The inhibitory effect of $R-2 m A b$ was more potent than that of $R-1 m A b$, and combination treatment with both mAbs almost completely attenuated fibrosis development. Our in vitro study showed that VEGF treatment significantly stimulated proliferation of both activated hepatic stellate cells (HSC) and sinusoidal endothelial cells (SEC). VEGF also significantly increased $\alpha 1$ (I)-procollagen mRNA expression in activated HSC.

Conclusions: These results suggest that the interaction of VEGF and its receptor, which reflected the combined effects of both on HSC and SEC, was a prerequisite for liver fibrosis development. a

t is widely recognised that hepatic fibrosis development is associated with progression of chronic liver disease. ${ }^{1}$ It has been shown that capillarisation and phenotypic changes of the hepatic sinusoidal endothelial cells (SEC) occur during liver fibrosis development. ${ }^{2-4}$ The hepatic SEC are unique endothelial cells (EC) that show fenestration and lack of basement membrane. They reside both morphologically and functionally apart from the ordinary EC. ${ }^{5}$ Sinusoidal capillarisation involves changes in SEC, including loss of fenestration and deposition of a basement membrane, as well as alterations of the cell-cell and cell-matrix interactions in hepatic sinusoids..$^{2-6}$ This so called capillarisation of SEC results either from development of neovessels or from alteration of the preexisting sinusoids, both events possibly induced in response to angiogenic stimulation. ${ }^{6}$

Angiogenesis is the development of new vasculature from pre-existing blood vessels and/or circulating EC stem cells. ${ }^{7}$ Emerging evidence has shown that angiogenesis plays a pivotal role in many physiological and pathological processes, such as tumour growth, arthritis, psoriasis, and diabetic retinopathy. ${ }^{79}$ Although previous studies conducted to determine the molecular process associated with fibrosis and angiogenesis were performed independently, recent studies have revealed that both biological phenomena emerged synergistically. ${ }^{6}$ It was shown that neovascularisation significantly increased during the development of liver fibrosis in both human and animal experimental studies. ${ }^{10-12}$ Furthermore, a semisynthetic analogue of fumagilin, TNP-470, which possesses antiangiogenic activity, suppressed experimental liver fibrosis development. ${ }^{13}$ These results suggest that angio- genesis also plays an important role in the development of liver fibrosis.

Angiogenesis is regulated by the net balance between proangiogenic factors and angiogenic inhibitors. To date, many positive and negative angiogenic modulating factors have been identified. Among these, vascular endothelial growth factor (VEGF), also known as vascular permeability factor, is the most potent in the angiogenesis process. ${ }^{14-16}$ Emerging evidence has shown that VEGF plays a pivotal role in many cases of physiological and pathological angiogenesis. VEGF is not only an angiogenic factor, it is also known as a survival factor of EC. ${ }^{17-19}$ Regarding liver fibrosis, it has been shown recently that VEGF expression significantly increased during the course of liver fibrosis development in experimental studies, and that VEGF participated in sinusoidal capillarisation in the liver. ${ }^{11}{ }^{12} 20$ In addition to hepatocytes, activated hepatic stellate cells (HSC), which play an important role in liver fibrogenesis, have been shown to increase VEGF expression during activation. ${ }^{21-24}$

Abbreviations: $\alpha$-SMA, $\alpha$ smooth muscle actin; ALT, aminotransferase aspartate; A-M, Azan-Mallory; ECM, extracellular matrix; EC endothelial cells; HSC, hepatic stellate cells; IgG, immunogloblin G; $\mathrm{mAb}$, neutralising monoclonal antibody; $P C R$, polymerase chain reaction; P-III-P, procollagen III-N-peptide; R- 1 mAb, VEGFR-1 monoclonal antibody; R-2mAb, VEGFR-2 monoclonal antibody; SEC, hepatic sinusoidal endothelial cells; VEGF, vascular endothelial growth factor; VEGFR-1, fms-like tyrosine kinase (flt-1); VEGFR-2, kinase-insert domain-containing receptor/fetal liver kinase-1 (KDR/Flk-1); vWF, von Willebrand factor. 
Two tyrosine kinases, fms-like tyrosine kinase (flt-1: VEGFR-1) and the kinase insert domain-containing receptor/ murine homologue, fetal liver kinase-1 (KDR/Flk-1: VEGFR2 ), both of which are type III tyrosine kinase receptors, have been identified as the main VEGF receptors. By binding with high affinity to these two receptors, VEGF can stimulate EC proliferation, migration, and differentiation, and can induce angiogenesis in vitro and in vivo. ${ }^{1625}$ It has been shown that these two receptors serve different biological roles in many pathological events. ${ }^{26-28}$ It has been reported that VEGFR-2 plays a more important role both in vitro and in vivo. ${ }^{15} 1629$ However, recent studies have revealed that VEGFR-1 also plays certain roles in pathological angiogenesis, such as tumour growth. ${ }^{30-34}$ It has been shown that expression of VEGFR-1 and VEGFR-2 was induced during activation of HSC in vitro, although the upregulation patterns were different under different culture conditions, such as hypoxia and $\mathrm{CCl}_{4}$ treatment. ${ }^{22-24}$ In experimental liver fibrogenesis, it has been reported that VEGFR-1 expression increased in the liver, and VEGFR-2 was constitutively highly expressed although its expression level was not significantly altered. ${ }^{1123}$ The in vivo role of the interaction between VEGF and its receptor in liver fibrosis development has not yet been elucidated.

In the present study, using the specific neutralising monoclonal antibodies of VEGFR-1 and VEGFR-2, we examined the biological role of VEGF and its receptors in the progression of liver fibrosis.

\section{METHODS}

\section{Animals}

Male BALB/c mice, aged six weeks, were purchased from Japan SLC Inc. (Hamamatsu, Shizuoka, Japan). They were housed in stainless steel mesh cages under controlled conditions (temperature $23 \pm 3^{\circ} \mathrm{C}$ and relative humidity $50 \pm 20 \%$ ), with $10-15$ air changes per hour and light illumination for 12 hours a day. The animals were allowed access to food and tap water ad libitum throughout the acclimatisation and experimental periods.

\section{Compounds and animal treatment}

Anti-VEGFR-1 and VEGFR-2 specific neutralising antibodies (R-1mAb and R-2mAb, respectively) were generated as described previously. ${ }^{313-36}$ Briefly, these antibodies were produced under large scale culture conditions in serum free media. The monoclonal antibodies (mAbs) were purified from conditioned media by affinity chromatography on a Gammabind-G-Sepharose column (Pharmacia Biotech, Piscataway, New Jersey, USA). The purity of the respective receptors was $>99 \%$, as determined by sodium dodecyl sulphatepolyacrylamide gel electrophoresis, and were verified to be free of endotoxin $(<1 \mathrm{EU} / \mathrm{ml})$ using a limulus amoebocyte lysate endotoxin detection kit (Pyrogen Tplus, Bio-Whittaker, Walkersville, Maryland, USA). It has been shown that R-2mAb exerts a VEGFR-2 inhibitory effect in a dose dependent manner, and that the maximal effect is achieved at a dose of 800 $\mu \mathrm{g} /$ mouse administered twice a week. ${ }^{34}{ }^{37}$ We thus employed this dose in the current study.

Mice were divided into four groups ( $\mathrm{n}=10$ in each group). All experimental groups received $\mathrm{CCl}_{4}(2 \mathrm{ml} / \mathrm{kg} /$ body weight dissolved in $150 \mu \mathrm{l}$ of corn oil) twice a week to develop liver fibrosis. After two weeks of treatment with $\mathrm{CCl}_{4}, \mathrm{R}-1 \mathrm{mAb}$ and $\mathrm{R}-2 \mathrm{mAb}(800 \mu \mathrm{g} / \mathrm{mouse})$ were administered intraperitoneally to group 2 (G2) and group 3 (G3) twice a week on days different from those on which $\mathrm{CCl}_{4}$ was injected, respectively. In group 4 (G4), both R-1mAb and R-2mAb were administered simultaneously. Animals in group 1 (Gl) received the same amount of control immunogloblin $\mathrm{G}$ (IgG) as described previously. ${ }^{35}{ }^{36}$ Mice which received only corn oil were examined as a negative control group. After eight weeks of treatment with $\mathrm{CCl}_{4}$, all mice were killed under anaesthesia.

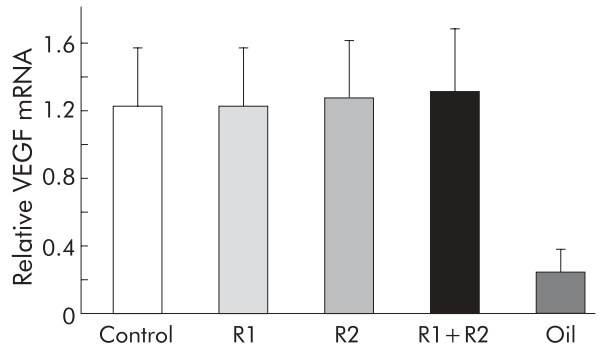

Figure 1 Vascular endothelial growth factor (VEGF) mRNA expression in the $\mathrm{CCl}_{4}$ treated liver. VEGF mRNA expression was examined by real time polymerase chain reaction as described in the methods section. Hepatic VEGF expression increased during liver fibrosis development. Neither R-1 mAb nor R-2mAb treatment altered VEGF gene expression during development of fibrosis. Control, immunogloblin $\mathrm{G}$ treated mice (800 $\mathrm{\mu g} / \mathrm{mouse}$ ) (G1); R1, R2,

R- $1 \mathrm{mAb}$ and $\mathrm{R}-2 \mathrm{mAb}$ treated mice $(800 \mu \mathrm{g} / \mathrm{mouse})$ (G2 and $\mathrm{G} 3$, respectively); $\mathrm{R} 1+\mathrm{R}-2, \mathrm{R}-1 \mathrm{mAb}$ and $\mathrm{R}-2 \mathrm{mAb}$ combination treated group (G4); Oil, corn oil injected negative control mice. Data are means $(S D)(n=5)$.

All animal procedures were performed according to approved protocols and in accordance with the standard recommendations for the proper care and use of laboratory animals.

\section{Histological and immunohistochemical examinations}

In all experimental groups, $5 \mu \mathrm{m}$ thick sections of formalin fixed and paraffin embedded livers were processed routinely for Azan-Mallory (A-M) staining for determination of liver fibrosis development. Immunohistochemical staining of $\alpha$ smooth muscle actin ( $\alpha$-SMA) was performed as previously described using paraffin embedded sections with a primary anti- $\alpha$ - SMA antibody (Dako, Kyoto, Japan).$^{38-40}$ Semiquantitative analyses of fibrosis development and the immunopositive cell area were carried out with the Fuji-BAS 2000 image analysing system (Fuji, Tokyo, Japan) in six ocular fields (40× magnification) per specimen from five mice. We did not count $\alpha$-SMA positive vessels in the portal area which were assumed to be hepatic arteries. We only included $\alpha$-SMA positive cells in the sinusoidal lining for image analysis. ${ }^{38-40}$

\section{Hepatic hydroxyproline content and serum markers}

Hepatic hydroxyproline content was determined as previously described with $200 \mathrm{mg}$ of frozen samples. ${ }^{40}$ The hydroxyproline content was expressed as $\mu \mathrm{g} / \mathrm{g}$ wet liver. Alanine aminotransferase aspartate (ALT) and total bilirubin were assessed using routine laboratory methods. Serum hyaluronic acid and procollagen III-N-peptide (P-III-P) were also measured as described previously. ${ }^{38}$

\section{Immunoprecipitation}

To determine whether R-1mAb and R-2mAb at a dose of 800 $\mu \mathrm{g} /$ mouse suppressed autophosphorylation of the respective receptors in the liver, immunoprecipitation was performed as previously described ${ }^{35}$ Fifteen minutes after R- $1 \mathrm{mAb}$ and $\mathrm{R}-2 \mathrm{mAb}$ were injected intraperitoneally, the liver was resected from three mice in each group and snap frozen immediately. The liver pool lysate solution was concentrated and used for immunoprecipitation. To conduct immunoprecipitation, liver lysates were immunoprecipitated with antiphosphotyrosine before conducting sodium dodecyl sulphate- polyacrylamide gel electrophoresis. Antityrosine (4G10) was purchased from Upstate Biotechnology (New York, USA) and anti-VEGFR-2 (C-1158) and VEGFR-1 (C-17) were obtained from SantaCruz (California, USA). Before western blotting, we stained each membrane with Ponceau solution (Sigma, Michigan, USA) to confirm that the same amounts of protein were immunoprecipitated (data not shown). The blots were developed using an amplified alkaline phosphatase immunoblot assay kit (Bio-Rad, California, USA). 

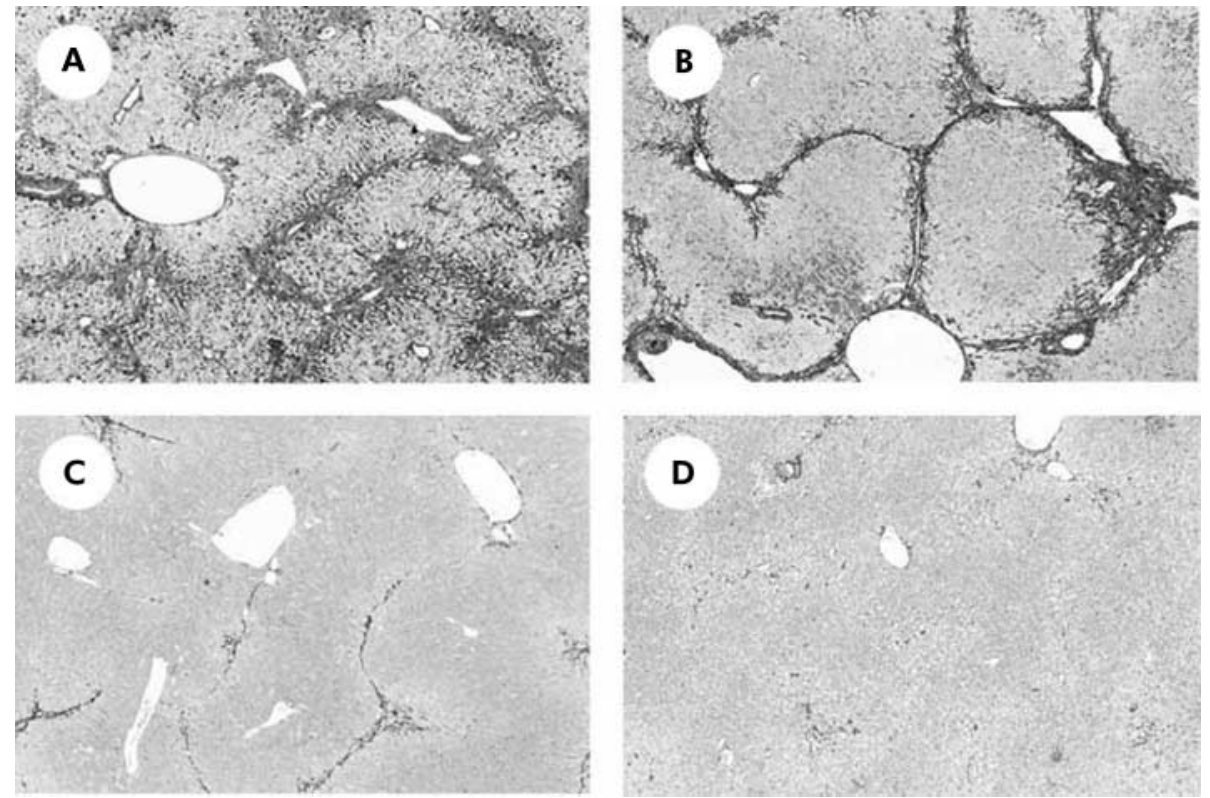

Figure 2 Microphotographs of liver sections from $\mathrm{CCl}_{4}$ treated mice. (A) Control immunogloblin $\mathrm{G}$ treated group after $\mathrm{CCl}_{4}$ treatment $(800$ $\mu \mathrm{g} / \mathrm{mouse}$ ) (G1). (B, C) R-1 mAb and R-2mAb treated ( $800 \mu \mathrm{g} /$ mouse) groups (G2 and G3, respectively). (D) R-1 $\mathrm{mAb}$ and R-2mAb combination treated group (G4). The livers in $\mathrm{G} 1$ show extensive fibrosis development. In $\mathrm{G} 2$ and $\mathrm{G} 3$, liver fibrosis development was significantly attenuated, and the inhibitory impact was more potent with R-2mAb treatment than with R-1mAb treatment. Fibrosis development was almost completely abolished in the livers of G4 (A-M staining, 40x).

\section{RNA expression of VEGF, CD-31, and $\alpha 1$-(I)-procollagen by real time polymerase chain reaction}

The VEGF, CD-31, which is used widely as a marker for neovascularisation, and $\alpha \mathrm{l}-(\mathrm{I})$ - procollagen mRNA expression were evaluated by real time polymerase chain reaction (PCR), as described previously. ${ }^{381}$ mRNA was extracted from the whole liver of the animals in each experimental group $(n=5)$. For cDNA synthesis, Taqman reverse transcription reagents were used as described in the manufacturer's manual of the ABI Prism 7700 Sequence Detection System (PE Applied Biosystems, Foster City, California, USA), which was used for real time PCR amplification following the Taqman Universal PCR Master Mix Protocol (PE Applied Biosystems). Relative quantitation of gene expression was performed as described in the manual, using glyceraldehyde-3-phosphate dehydrogenase as an internal control. The threshold cycle and standard curve method were used for calculating the relative amount of the target RNA, as described for PE. The following temperatures were employed: hold at $50^{\circ} \mathrm{C}$ for two minutes, hold at $60^{\circ} \mathrm{C}$ for 30 minutes, hold at $94^{\circ} \mathrm{C}$ for five minutes, cycle 45 repeats at $94^{\circ} \mathrm{C}$ for one minute, at $55^{\circ} \mathrm{C}$ for one minute, and at $72^{\circ} \mathrm{C}$ for one minute. To prevent genomic DNA contamination, all RNA samples were subjected to DNase I digestion and checked by 40 cycles of PCR to confirm the absence of amplified DNA.

\section{Isolation and culture of HSC and SEC}

$\mathrm{R}-\mathrm{ImAb}$ and R-2mAb only react with mice receptors and not with those of other species, such as the rat. ${ }^{31}{ }^{42}$ Although we attempted several times to isolate pure HSC from the liver of mice, contamination with other types of non-parenchymal cells, such as EC, could not be ruled out. Furthermore, the yield of purified HSC from mice was too low to perform several experiments, as described previously. ${ }^{38}$ We thus employed HSC from the liver of the rat, and examined the effect of VEGF treatment on VEGF-receptor interaction in activated HSC.

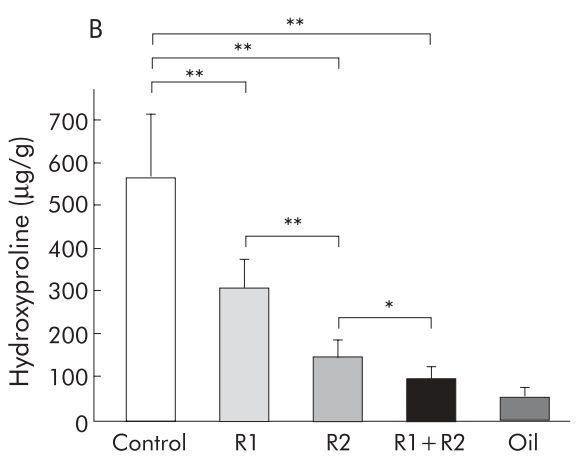

Figure 3 Effects of $R-1 m A b$ and $R-2 m A b$ on fibrosis area $(A)$ and hepatic hydroxyproline content $(B)$ in the $C C l_{4}$ treated liver. (A) Fibrosis area was evaluated by an image analyser, as described in the methods section. $R-1 \mathrm{mAb}$ and R-2mAb significantly suppressed liver fibrosis development compared with the control group $(\mathrm{p}<0.01)$, and the inhibitory impact was more potent with $R-2 \mathrm{mAb}$ treatment than that with $R-1 \mathrm{mAb}$ treatment $(p<0.01)$. The combination treatment with both $\mathrm{mAbs}$ revealed further inhibition compared with that of $\mathrm{R}-2 \mathrm{mAb}$ alone $(p<0.05)$. (B) The inhibitory effects of $R-1 \mathrm{mAb}$ and $R-2 \mathrm{mAb}$ on hepatic hydroxyproline content exerted behaviours similar to those on fibrosis area. Control, immunogloblin G treated mice ( $800 \mu \mathrm{g} / \mathrm{mouse}$ ) (G1); R1, R2, R-1 mAb and R-2mAb treated mice (800 $\mu \mathrm{g} / \mathrm{mouse})$ (G2 and G3, respectively); $\mathrm{R} 1+\mathrm{R} 2, \mathrm{R}-1 \mathrm{mAb}$ and $\mathrm{R}-2 \mathrm{mAb}$ combination treated group (G4); Oil, corn oil injected negative control mice. Data are means (SD) $(n=5) .{ }^{*} p<0.05,{ }^{* *} p<0.01$ between the indicated groups. 
Table 1 Effect of R-1 and R-2 mAb on several markers in animals treated with $\mathrm{CCl}_{4}$

\begin{tabular}{llccc}
\hline Group & Hyaluronic acid $(\mathrm{ng} / \mathrm{ml})$ & P-III-P $(\mathrm{ng} / \mathrm{ml})$ & ALT $(\mathrm{U} / \mathrm{ml})$ & Total bilirubin (mg/dl) \\
\hline Contro I & $190.2(27.5)$ & $46.3(6.4)$ & $242.4(51.8)$ & $1.4(0.2)$ \\
R1 mAb & $82.7(17.4)^{* *}$ & $20.6(6.0)^{* *}$ & $216.4(55.7)$ & $1.1(0.2)$ \\
R2 mAb & $28.7(14.3) \dagger \dagger$ & $7.1(3.4)^{\dagger \dagger}$ & $233.8(60.8)$ & $1.2(0.2)$ \\
R1+R2 & $18.6(7.9)$ & $3.8(1.9)$ & $226.3(54.5)$ & $1.1(0.3)$ \\
Oil & $11.4(3.0)$ & $2.4(1.1)$ & $45.1(7.3)$ & $0.6(0.2$ \\
\hline
\end{tabular}

Data are means (SD) $(n=8)$

P-III-P, procollagen III-N-peptide; ALT, aminotransferase aspartate; R1 mAb, VEGFR-1 monoclonal antibody; R2 mAb, VEGFR-2 monoclonal antibody; R1+R2, R1 mAb+R2 mAb.

$R 1+R 2, R 1 m A b+R 2 m A b$.
${ }^{* *} p<0.01$ compared with the control group; $\dagger+p<0.01$ compared with the $R 1 \mathrm{mAb}$ treated group.

Liver HSC were isolated from the liver of F344 rats, as described previously, ${ }^{38}$ with a minor modification. Briefly, the liver was perfused with Krebs-Ringer solution followed by $0.1 \%$ pronase $\mathrm{E}$ and $0.032 \%$ collagenase (Nakarai, Kyoto, Japan) solution at $37^{\circ} \mathrm{C}$. The digested liver was cut, minced, and incubated in Krebs-Ringer solution containing 0.08\% pronase E, $0.04 \%$ collagenase, and $20 \mu \mathrm{l} / \mathrm{ml}$ DNase for $30 \mathrm{~min}$ utes at $37^{\circ} \mathrm{C}(\mathrm{pH} \mathrm{7.3)}$. After passage through a nylon mesh, cells were centrifuged at $450 \mathrm{~g}$ for eight minutes. The HSC enriched fraction was obtained by centrifugation in $8.2 \%$ Nycodenz (Nycomed Pharma AS, Oslo, Norway) solution at $1400 \mathrm{~g}$ for 20 minutes. HSC in the upper white layer were washed by centrifugation at $450 \mathrm{~g}$ for eight minutes and suspended in DMEM medium containing $10 \%$ fetal calf serum, $100 \mathrm{U} / \mathrm{ml}$ penicillin, and $100 \mathrm{mU} / \mathrm{ml}$ streptomycin. Cell viability was over $95 \%$, as determined by the Trypan blue exclusion test. Cells were plated at a density of $5 \times 10^{5}$ cells $/ \mathrm{ml}$ on either collagen I, an established model of culture activation, ${ }^{43}$ or basement membrane-like EHS matrix for six days in the presence of $20 \%$ fetal calf serum, serum starved for 48 hours, and treated with doses of 10 and $100 \mathrm{ng} / \mathrm{ml}$ of human recombinant VEGF (RED systems Inc. Minneapolis, Minnesota, USA), as described previously. ${ }^{24}$ SEC were isolated from the rat liver with collagenase followed by differential centrifugation, as described previously, ${ }^{44}$ and grown in HuMedia-EG2 medium (Kurabo, Osaka, Japan) on a collagen I coated dish supplied with human recombinant VEGF $(10 \mathrm{ng} / \mathrm{ml})$ as VEGF is a prerequisite for SEC survival. ${ }^{45}$

\section{In vitro proliferation assay}

The effects of VEGF on in vitro proliferation of activated HSC and SEC were determined using the MTT assay, as described previously ${ }^{46}$ Briefly, cell proliferation was quantified via conversion of tetrazolium, 3-(-4,5-diethylthiazol-2-yl)-2,5diphenyltetrazolium bromide (MTT) by cells cultured in 96 well plates. Absorbance with a $540 \mathrm{~nm}$ filter represents conversion to formazan, which is directly proportional to the number of living cells. Absorbance was read with an ELISA plate recorder ( $n=6$ per group).

\section{Statistical analysis}

To assess the statistical significance of intergroup differences in quantitative data, the Mann-Whitney $U$ test was used to compare mean values between the two groups. The KruskalWallis test was used to compare mean values between more than two groups.

\section{RESULTS}

\section{VEGF mRNA expression}

Firstly, we examined VEGF mRNA expression during $\mathrm{CCl}_{4}$ induced liver fibrosis development. Similar to previous reports, ${ }^{11}{ }^{12}$ hepatic VEGF expression significantly increased during liver fibrosis development after $\mathrm{CCl}_{4}$ treatment. Neither R-lmAb nor R- 2mAb treatment altered VEGF gene expression during development of fibrosis (fig 1). We performed a preliminary routine reverse transcription PCR, and found that among the alternative splicing mouse VEGF genes, $V_{E G F_{164}}$ and $\mathrm{VEGF}_{120}$ were abundant in the $\mathrm{CCl}_{4}$ treated liver (data not shown).

\section{Histological findings and fibrosis markers}

A-M staining revealed that eight weeks of treatment with $\mathrm{CCl}_{4}$ resulted in marked liver fibrosis development (fig 2A). Both $\mathrm{R}-1 \mathrm{mAb}$ and $\mathrm{R}-2 \mathrm{mAb}$ treatment significantly suppressed fibrosis development (fig $2 \mathrm{~B}, 2 \mathrm{C}$, respectively), and the combination treatment of $\mathrm{R}-1 \mathrm{mAb}$ and $\mathrm{R}-2 \mathrm{mAb}$ almost completely attenuated $\mathrm{CCl}_{4}$ induced liver fibrosis (fig 2D). No fibrosis development was found in the corn oil treated group, and the low dose of R-1mAb (400 $\mu \mathrm{g} /$ mouse) did not exert such an inhibitory effect (data not shown). Densitometric analysis showed that the fibrosis areas (fig 3A) mostly corresponded to the histological findings. Although both R-1mAb and R-2mAb significantly suppressed liver fibrosis development compared with the control IgG treated group $(\mathrm{p}<0.01)$, the inhibitory impact was more potent with R-2mAb than with R-1mAb treatment $(p<0.01)$. The combination treatment with both mAbs revealed further inhibition compared with that of $\mathrm{R}-2 \mathrm{mAb}$ alone $(\mathrm{p}<0.05)$. Hepatic hydroxyproline content showed similar results to those of fibrosis area (fig 3B). These results suggest that both VEGFR-1 and VEGFR-2 play important roles in liver fibrogenesis, and that the role of VEGFR-2 is more predominant than that of VEGFR-1. The serum fibrosis markers, hyaluronic acid and P-III-P, were also significantly suppressed by treatment with R-1mAb and R-2mAb, whereas serum ALT and total bilirubin levels did not change with the use of $\mathrm{R}-1 \mathrm{mAb}$ and $\mathrm{R}-2 \mathrm{mAb}$ (table 1 ). We also examined the

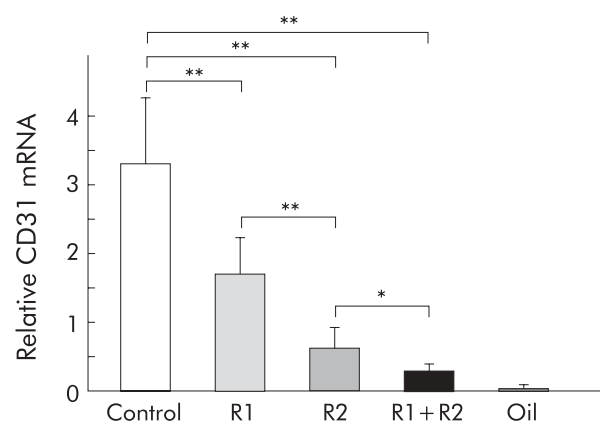

Figure 4 Effects of $R-1 m A b$ and $R-2 m A b$ on neovascularisation in the liver. CD3 1 mRNA expression was examined by real time polymerase chain reaction, as described in the methods section. CD3 1 gene expression was significantly increased during liver fibrosis development. Treatment with R-1mAb and R-2mAb significantly attenuated neovascularisation in the liver. Suppression of angiogenesis by treatment with $R-1 \mathrm{mAb}$ and $\mathrm{R}-2 \mathrm{mAb}$ was of $\mathrm{a}$ similar magnitude to that of inhibition of fibrosis areas. Control, immunogloblin $G$ treated mice (800 $\mathrm{gg} / \mathrm{mouse})(\mathrm{G} 1)$; R1, R2, R- $1 \mathrm{mAb}$ and $\mathrm{R}-2 \mathrm{mAb}$ treated mice $(800 \mu \mathrm{g} / \mathrm{mouse})$ ( $\mathrm{G} 2$ and $\mathrm{G} 3$, respectively); $R 1+R 2, R-1 m A b$ and $R-2 m A b$ combination treated group (G4); Oil, corn oil injected negative control mice. Data are means (SD) $(n=5) .{ }^{*} p<0.05,{ }^{*}{ }^{*}<<0.01$ between the indicated groups. 

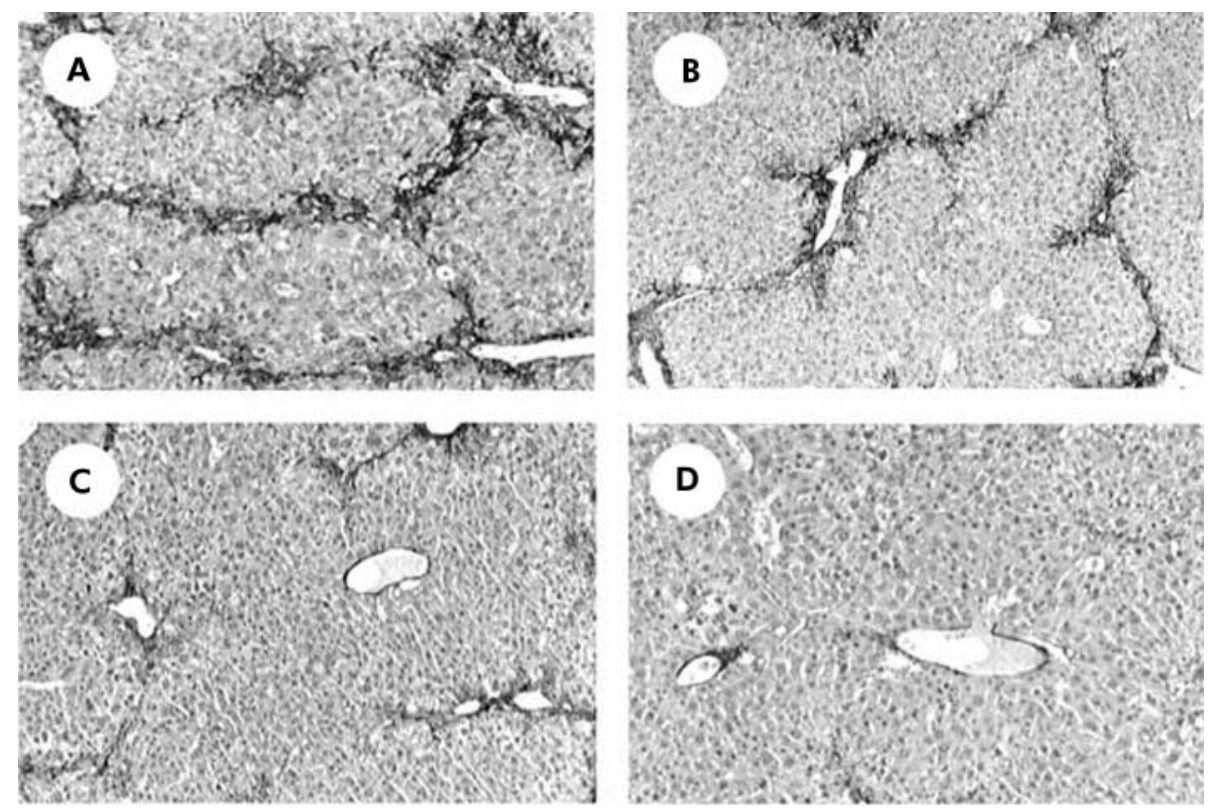

Figure 5 Immunohistochemical analysis of $\alpha$ smooth muscle actin ( $\alpha$-SMA). Immunopositive cells of $\alpha$-SMA were significantly reduced in the livers of $R-1 m A b(B), R-2 m A b(C)$, and the combination of R-1mAb and R-2mAb treated groups (D) compared with the control group (A) (G1) (magnification $\times 40)$.

effects of R-1mAb and R-2mAb on the acute liver injury and early liver fibrogenesis step. It has been shown that Masson's trichrome positive connective tissue accumulation could be observed on day 7 after $\mathrm{CCl}_{4}$ treatment. ${ }^{47}$ Two or seven days after $\mathrm{CCl}_{4}$ treatment, R-1mAb and R-2mAb did not alter ALT levels in the liver (data not shown). This indicated that the inhibitory effect of mAbs was not a secondary response to a cytoprotective effect against $\mathrm{CCl}_{4}$. Body and liver weights when the mice were killed were not significantly different between the control, R-1mAb treated, and R-2mAb treated groups (data not shown).

\section{Neovascularisation}

To examine whether the inhibitory effects of R-lmAb and $\mathrm{R}-2 \mathrm{mAb}$ were associated with suppression of neovascularisation in the liver, we evaluated the angiogenic response during liver fibrosis development. We performed a preliminary immunohistochemical analysis of the von Willebrand factor (vWF) related antigen on sections from all experimental groups, and found that $\mathrm{R}-1 \mathrm{mAb} / \mathrm{R}-2 \mathrm{mAb}$ treatment significantly suppressed vWF positive vessels. However, it was hard to accurately evaluate vWF positive cells because of difficulties in identifying the little slit vessels in the R- $1 \mathrm{mAb}$ and $\mathrm{R}-2 \mathrm{mAb}$ combination treated group (data not shown). It has been reported that CD34 is a more sensitive marker than vWF related antigen. ${ }^{4} \mathrm{CD} 31$ was also shown to be a sensitive marker in EC. ${ }^{48}$ Among these markers, it has been reported that CD34 expression may be decreased by VEGF. ${ }^{49}$ We thus used CD31 expression in the current study.

We performed real time PCR analysis of CD31 gene expression to evaluate neovascularisation in the liver. Figure $4 \mathrm{dem}$ onstrates that CD31 gene expression was significantly increased in association with liver fibrosis development. Similar to fibrosis area, both R-1mAb and R-2mAb significantly suppressed CD31 gene expression compared with the control group $(\mathrm{p}<0.01)$. The inhibitory impact was more potent with $\mathrm{R}-2 \mathrm{mAb}$ treatment than that with $\mathrm{R}-\mathrm{lmAb}$ treatment $(\mathrm{p}<0.01)$, and the combination treatment of both mAbs almost abolished neovascularisation in the liver. Noteworthy was the finding that suppression of angiogenesis by treatment with R- $1 \mathrm{mAb}$ and R-2mAb was of a similar magnitude to that of inhibition of fibrosis areas.
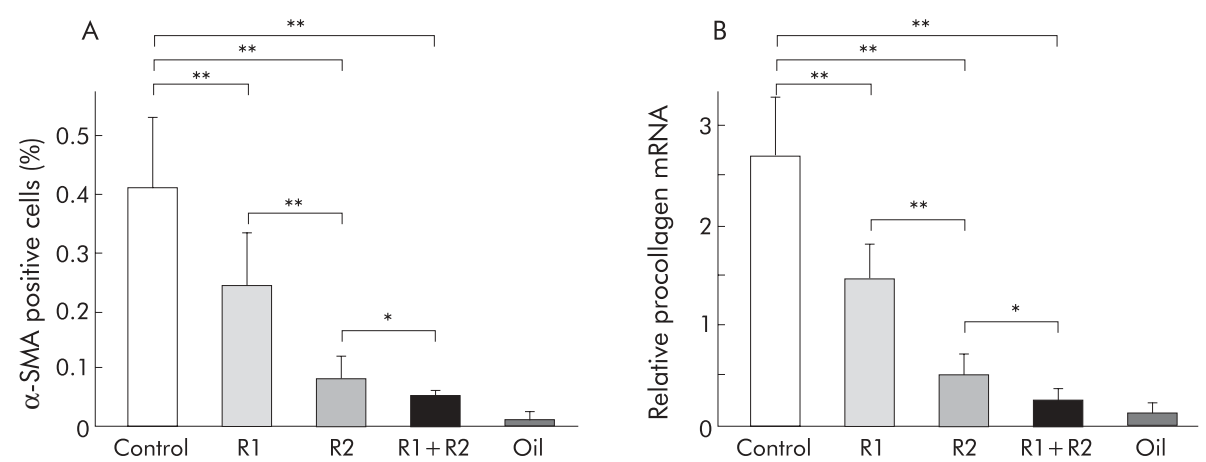

Figure 6 Densitometric analysis of $\alpha$ smooth muscle actin $(\alpha-S M A)$ positive cells $(A)$ and $\alpha 1$ - (I)-procollagen mRNA expression $(B)$ in the CCl treated liver. $\alpha$-SMA positive activated hepatic stellate cells and $\alpha 1$-(I)-procollagen mRNA were significantly reduced by $R-1 \mathrm{mAb}$ and $R-2 \mathrm{~mA} b$ treatment. The inhibitory effect of R-2mAb was more potent than that of R-1mAb. The inhibitory effects of R- $1 m A b$ and R-2mAb on $\alpha-S M A$ and $\alpha 1$-(I)- procollagen expression exerted almost parallel reductions. Control, immunogloblin $G$ treated mice ( $800 \mathrm{\mu g} / \mathrm{mouse})(\mathrm{G} 1) ; \mathrm{R} 1, \mathrm{R} 2$, R- $1 \mathrm{mAb}$ and $\mathrm{R}-2 \mathrm{mAb}$ treated mice $(800 \mathrm{\mu g} / \mathrm{mouse}$ ) (G2 and G3, respectively); R $1+R 2, R-1 \mathrm{mAb}$ and $\mathrm{R}-2 \mathrm{mAb}$ combination treated group (G4); Oil, corn oil injected negative control mice. Data are means (SD) $(n=5) .{ }^{*} p<0.05,{ }^{* *} p<0.01$ between the indicated groups. 
2

3

4

5

Flt-1

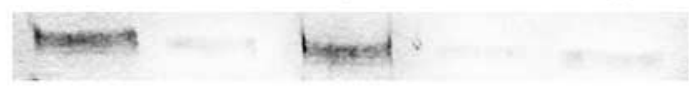

Flk-1

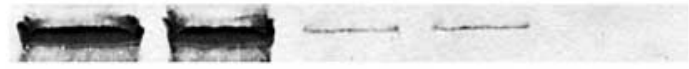

Figure 7 Effects of R- $1 m A b$ and R-2mAb on the activation of vascular endothelial growth factor (VEGF) receptors VEGFR-1 (fms-like tyrosine kinase (Flt-1)) and VEGFR-2 (kinase-insert domain-containing receptor/fetal liver kinase-1 (Flk-1)). Fifteen minutes after injection of $R-1 m A b$ and $R-2 m A b$, the liver was resected from three mice and pooled. The liver lysate was concentrated and used for immunoprecipitation, as described in the methods section. R- $1 \mathrm{mAb}$ and R-2mAb significantly inhibited tyrosine phosphorylation of the respective receptors. Neither activation of VEGFR-1 nor that of VEGFR-2 was altered by administration of $R-2 m A b$ and $R-1 m A b$, respectively. The activation level of VEGFR-1 was lower than that of VEGFR-2. Lane 1 immunogloblin $G$ treated control group (G1); lane 2, R- $1 \mathrm{mAb}$ treated group (G2); lane 3, R-2mAb treated group (G3); lane 4, $\mathrm{R}-1 \mathrm{mAb}$ and R-2mAb combination treated group (G4); and lane 5, corn oil treated negative control group.

\section{Effects of R-1 mAb and R-2mAb on HSC activation}

It has been reported that not only SEC, but also activated HSC, express both VEGFR-1 and VEGFR-2. ${ }^{23}{ }^{24}$ Immunohistochemical examination showed that $\alpha$-SMA positive cells were drastically reduced by treatment with $\mathrm{R}-1 \mathrm{mAb}$ and $\mathrm{R}-2 \mathrm{mAb}$ (fig 5A-5D). Computer assisted semiquantitative analysis showed that $\alpha$-SMA positive cells in the R-1mAb and R$2 \mathrm{mAb}$ treated groups were significantly reduced compared with the control group $(\mathrm{p}<0.01$ ) (fig $6 \mathrm{~A})$. We also performed real time PCR analysis to elucidate the effect of these mAbs on $\alpha \mathrm{l}-(\mathrm{I})$-procollagen mRNA expression. R-1mAb and $\mathrm{R}-2 \mathrm{mAb}$ also markedly suppressed mRNA expression of $\alpha 1-(\mathrm{I})$-procollagen in the liver compared with the control group ( $\mathrm{p}<0.01$ ) (fig 6B). The inhibitory effects of $\mathrm{R}-2 \mathrm{mAb}$ on both $\alpha$-SMA positive cells and $\alpha 1-(\mathrm{I})$-procollagen mRNA expression were significantly stronger than those of R-1mAb $(\mathrm{p}<0.01)$. The inhibitory effects of R-1mAb and R-2mAb on $\alpha$-SMA, $\alpha 1-(\mathrm{I})$-procollagen mRNA expression, and fibrosis area were almost identical, suggesting that suppression of HSC activation also contributed to the antifibrotic effect of these mAbs.
VEGFR-1 and VEGFR-2 receptor activation in situ

To determine whether R-1mAb and R-2mAb at the dose used in the current study ( $800 \mu \mathrm{g} /$ mouse) inhibited autophosphorylation in the liver, we investigated tyrosine phosphorylated VEGFR- 1 and VEGFR-2 in the liver after intraperitoneally injection of R- $\operatorname{lmAb}$ and R-2mAb. R- $\operatorname{lmAb}$ and $\mathrm{R}-2 \mathrm{mAb}$ significantly inhibited tyrosine phosphorylation of the respective receptors, and the combination treatment of $\mathrm{R}-1 \mathrm{mAb}$ and $\mathrm{R}-2 \mathrm{mAb}$ almost completely abolished phosphorylation of both receptors in the liver.

Neither activation of VEGFR-1 nor that of VEGFR-2 was altered by administration of R- $2 \mathrm{mAb}$ and $\mathrm{R}-1 \mathrm{mAb}$, respectively (fig 7).

\section{Effect of VEGF on cultured activated HSC and SEC}

It has been reported that HSC plated on collagen I are activated progressively whereas those on a basement membrane substratum resembling the normal subendothelial matrix of the liver (EHS matrix) remain quiescent. ${ }^{24}{ }^{50}$ We examined the effect of VEGF on HSC proliferation under different culture conditions. Figure 8A shows that both 10 and $100 \mathrm{ng} / \mathrm{ml}$ VEGF treatment did not increase in vitro proliferation on an EHS matrix whereas it was stimulated significantly on a collagen I coated dish $(\mathrm{p}<0.05)$, indicating that VEGF stimulated activated HSC proliferation but not quiescent HSC. We also examined whether VEGF increased synthesis of the extracellular matrix (ECM) component in activated HSC. As shown in fig 8B, VEGF treatment at a dose of $10 \mathrm{ng} / \mathrm{ml}$ significantly upregulated $\alpha \mathrm{l}$ - (I)-procollagen mRNA synthesis in activated HSC

We next examined the effect of VEGF on SEC proliferation. As it has been shown that VEGF is a survival factor for $\mathrm{SEC}^{45} \mathrm{we}$ chronologically examined the proliferation assay of SEC in the presence of VEGF $(10 \mathrm{ng} / \mathrm{ml})$. Figure $8 \mathrm{C}$ reveals that proliferation of SEC was significantly increased on stimulation with VEGF over time. Without VEGF, these cells rapidly atrophied and died in a few days. We also examined whether VEGF induced production of factors by SEC that may have an impact on HSC biology, such as platelet derived growth factor and transforming growth factor $\beta$. We found that neither factor was increased by treatment with VEGF in SEC (data not shown). In addition to the MTT assay, we performed the $[\mathrm{H}]^{3}$ incorporation experiment for in vitro proliferation of both HSC and SEC. Our results were similar to those of previously reported ${ }^{51}$ MTT and $[\mathrm{H}]^{3}$ incorporation assays (data not shown).
A

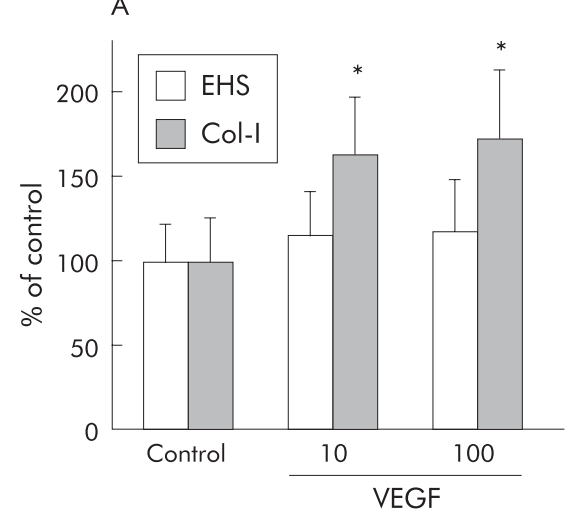

B

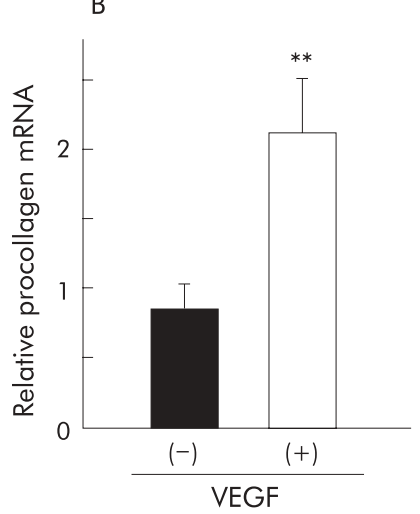

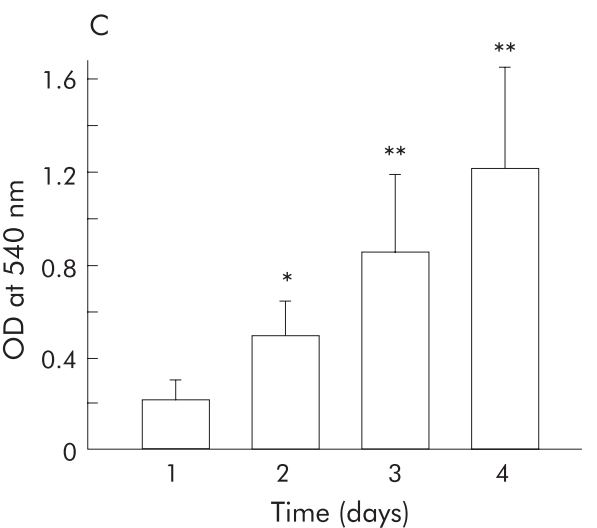

Figure 8 Effect of vascular endothelial growth factor (VEGF) on proliferation and $\alpha$ l - (I)-procollagen mRNA expression of activated hepatic stellate cells (HSC) and hepatic sinusoidal endothelial cells (SEC) in vitro. Cell proliferation and mRNA expression were measured by the MTT assay and real time polymerase chain reaction, as described in the methods section, respectively. (A) At doses of 10 and $100 \mathrm{ng} / \mathrm{ml}$, VEGF treatment did not increase the in vitro proliferation of HSC on an EHS matrix whereas it significantly stimulated proliferation on collagen I (Col-I). * $p<0.05$ compared with the control group. Control, untreated control group; VEGF, VEGF treated groups at doses of 10 and 100 $\mathrm{ng} / \mathrm{ml}$. (B) At a dose of $10 \mathrm{ng} / \mathrm{ml}$, VEGF significantly increased $\alpha 1$-(I)-procollagen mRNA synthesis in activated HSC. **p<0.01 compared with the VEGF untreated group. (C) Proliferation of SEC was significantly increased over time on stimulation with VEGF (10 ng/ml). OD, optical density. ${ }^{*} p<0.05,{ }^{* *} p<0.01$ compared with day 1 . Data are means (SD) $(n=5)$. 


\section{DISCUSSION}

Angiogenesis and fibrosis are key components in development, growth, wound healing, and regeneration. Recent studies have revealed that these processes commonly occur together in many disease states where neovascularisation is believed to initiate the pathological cascade. ${ }^{6}$ Among the identified angiogenic factors to date, VEGF is one of the most potent and central factors in many physiological and pathological processes. ${ }^{14-16}$ In liver fibrosis, it has been shown that VEGF expression increased in both human chronic liver diseases and experimental fibrogenesis. ${ }^{10-12}$ It has also been reported that VEGF expression correlates with chronic liver disease associated angiogenesis and sinusoidal capillarisation. ${ }^{12}{ }^{525}$ We also observed that VEGF gene expression significantly increased during fibrosis development associated with neovascularisation in the liver, and that suppression of VEGF-receptor interaction significantly attenuated progression of liver fibrosis and angiogenesis.

The biological activities of VEGF are mediated mainly via two type III tyrosine kinase receptors-namely, VEGFR-1 and VEGFR-2-which serve different roles in angiogenesis and signal transduction pathways. ${ }^{15} 162628$ It has been reported that VEGFR-2 plays a more important role both in vitro and in vivo in several biological events. ${ }^{15} 163536$ Overexpression of VEGFR-2 in porcine EC caused actin reorganisation, chemotaxis, and mitogenesis in response to VEGF, although VEGFR-1 expression in the same cells had a minimal effect in vitro. ${ }^{28}$ However, recent studies have revealed that VEGFR-1 is also involved in pathological angiogenesis, such as tumour growth. ${ }^{30-34}$ In the present study, we found that inhibition of either VEGFR-1 or VEGFR-2 significantly attenuated liver fibrogenesis accompanied by angiogenesis suppression, and that treatment with $\mathrm{R}-2 \mathrm{mAb}$ was more potent than that with $\mathrm{R}-1 \mathrm{mAb}$. The combination treatment with both mAbs almost completely attenuated liver fibrogenesis. These results indicate that VEGFreceptor interaction is a major regulator of the process of liver fibrosis. Both VEGFR-1 and VEGFR-2 were involved in liver fibrogenesis, and signalling through VEGFR-2 was a predominant pathway compared with that via VEGFR-1.

It is now recognised that activated HSC play an important role in liver fibrosis development. ${ }^{154}$ In addition to EC, recent studies have shown that expression of VEGF and its receptor occurs in activated HSC. ${ }^{22-24}$ This indicates that the cellular targets of VEGF are not confined to EC, and that VEGF responses reflect the combined effects on both EC and HSC Recently, it has been shown that hypoxia induced VEGF expression was associated with angiogenesis and liver fibrogenesis. The authors showed that hepatic VEGFR-1 expression increased in liver fibrogenesis, which probably originated from activated HSC. ${ }^{11}$ The in vitro study showed that VEGFR-1 was selectively increased in activated HSC under hypoxic conditions whereas expression of VEGFR-2 was not upregulated. ${ }^{23}$ However, it should be noted that VEGFR-2 was constitutively expressed in activated HSC, and that the expression level of VEGFR-2 was much higher than that of VEGFR-1. ${ }^{11}{ }^{23}{ }^{24}$ We found that activated $\alpha$-SMA positive HSC and $\alpha \mathrm{l}-(\mathrm{I})$-procollagen mRNA were significantly suppressed by $\mathrm{R}-\operatorname{lmAb}$ and $\mathrm{R}-2 \mathrm{mAb}$. It has been reported that $\alpha$-SMA expression in activated HSC may be downregulated by VEGF. ${ }^{21}$ The authors also claimed that VEGF did not affect proliferation of activated HSC in vitro. In contrast, we and others have shown different results under different culture conditions,$^{24}$ suggesting that VEGF exerts a different biological effect on activated HSC under different culture conditions. After liver injury, HSC proliferate and become activated to the myofibroblastic phenotype, which is characterised by an increase in expression of $\alpha$-SMA. ${ }^{1}$ As it is now widely recognised that $\alpha$-SMA is a useful and reliable marker for in vivo fibrogenesis, ${ }^{13840}$ we also employed this marker in the current study.
We also found that VEGF stimulated proliferation of activated HSC in vitro, indicating that VEGF-receptor interaction in HSC also plays an important role in liver fibrogenesis. We found that HSC did not respond to VEGF when they were cultured on Matrigel. Matrigel may sequester VEGF as it can bind with the proteoglycans of Matrigel. However, we found similar effects with low and high exogenous VEGF treatment ( $10 \mathrm{ng} / \mathrm{ml}$ and $100 \mathrm{ng} / \mathrm{ml}$, respectively). With high doses of VEGF, we assume that VEGF can act on HSC even if Matrigel may sequester some part of VEGF. A similar effect of VEGF on activated HSC in Matrigel has been reported. ${ }^{24}$

It would be important to elucidate the binding sites of $\mathrm{R}-\mathrm{ImAb}$ and R-2mAb during liver fibrogenesis. We attempted to localise these binding sites of mAbs by immunohistochemical double staining but we failed to obtain good results. The background was very intense, and interpretation was very difficult (data not shown). Furthermore, the specific role of each receptor in activated HSC remains obscure at this time as we could not obtain specific R- $1 \mathrm{mAb}$ and $\mathrm{R}-2 \mathrm{mAb}$ for the rat. When mAbs against rat VEGFR-1 and VEGFR-2 become available, further studies may elucidate the role of each receptor in liver fibrogenesis.

VEGF was originally identified as a vascular permeability factor that increased microvessel permeability approximately 50000 times more than histamine..$^{14}{ }^{16} 27$ It induces extravasation of plasma proteins, leading to an increase in the ECM. It has also been reported that VEGF increased mRNA levels of connective tissue growth factor, which has known actions on ECM production..$^{55}$ In the current study, we found that VEGF significantly increased $\alpha \mathrm{l}(\mathrm{I})$-procollagen mRNA in activated HSC, indicating that VEGF stimulates liver fibrogenesis through both ECM production and proliferation in activated HSC. Nevertheless, it is well known that HSC are the primary ECM producing cell type but SEC also respond rapidly to injury by synthesising an isoform of the cellular fibronectin that stimulates HSC activation. ${ }^{56}$ They also produce ECM components, such as type IV collagen and several proteoglycans. ${ }^{57}{ }^{58}$ In addition to its angiogenic activity, VEGF may also stimulate fibrosis development through these biological activities.

In summary, hepatic VEGF mRNA expression was significantly increased during the development of fibrosis, and both $\mathrm{R}-\mathrm{lmAb}$ and $\mathrm{R}-2 \mathrm{mAb}$ treatment significantly attenuated the fibrogenesis associated with suppression of neovascularisation in the liver. The inhibitory effect of R-2mAb was more potent than that of R-1mAb, and the combination treatment with $\mathrm{R}-\mathrm{lmAb}$ and R-2mAb almost completely attenuated liver fibrosis development. $\alpha$-SMA positive activated HSC and $\alpha \mathrm{l}$-(I)-procollagen mRNA were significantly suppressed by R$1 \mathrm{mAb}$ and $\mathrm{R}-2 \mathrm{mAb}$, and VEGF stimulated proliferation of activated HSC in vitro. These results suggest that interaction between VEGF and its receptors, which reflected the combined effects of both on HSC and SEC, was a prerequisite for liver fibrosis development.

\section{ACKNOWLEDGEMENTS}

This work was supported in part by a Grant-in-Aid for Scientific Research (C-14570498) from the Japanese Ministry of Education, Science, Sports, and Culture.

\section{Authors' affiliations}

H Yoshiii, J Yoshii, Y Ikenaka, R Noguchi, K Yanase, T Namisaki, M Yamazaki, H Tsujinoue, H Imazu, H Fukui, Third Department of Internal Medicine, Nara Medical University, Nara, Japan S Kuriyama, T Masaki, Third Department of Internal Medicine, Kagawa Medical University, Kagawa, Japan

D J Hicklin, Y Wu, Department of Immunology, ImClone Systems Incorporated, New York, NY, USA

\section{REFERENCES}

1 Friedman SL. Cytokines and fibrogenesis. Semin Liver Dis 1999; 19:129-40. 
2 Park YN, Yang CP, Fernandez GJ, et al. Neoangiogenesis and sinusoidal "capillarization" in dysplastic nodules of the liver. Am J Surg Pathol 1998:22:656-62

3 Schaffner F, Popper H. Capillarization of hepatic sinusoids in man. Gastroenterology 1963;44:239-42

4 Tanigawa N, Lu C, Mitsui T, et al. Quantitation of sinusoid-like vessels in hepatocellular carcinoma: its clinical and prognostic significance. Hepatology 1997;26:1216-23.

5 Wisse E, De Zanger RB, Charels K, et al. The liver sieve: considerations concerning the structure and function of endothelial fenestrae, the sinusoidal wall and the space of Disse. Hepatology 1985;5:683-92.

6 Kalluri R, Sukhatme VP. Fibrosis and angiogenesis. Curr Opin Nephrol Hypertens 2000;9:413-18

7 Carmeliet P. Mechanisms of angiogenesis and arteriogenesis. Nat Med 2000;6:389-95.

8 Asahara T, Takahashi T, Masuda H, et al. VEGF contributes to postnatal neovascularization by mobilizing bone marrow-derived endothelial progenitor cells. Embo J 1999;18:3964-72.

9 Carmeliet $\mathbf{P}$, Jain RK. Angiogenesis in cancer and other diseases. Nature 2000;407:249-57

10 Ohmori S, Shiraki K, Sugimoto K, et al. High expression of CD34-positive sinusoidal endothelial cells is a risk factor for hepatocellular carcinoma in patients with $\mathrm{HCV}$-associated chronic liver diseases. Hum Pathol 2001:32:1363-70.

11 Corpechot C, Barbu V, Wendum D, et al. Hypoxia-induced VEGF and collagen I expressions are associated with angiogenesis and fibrogenesis in experimental cirrhosis. Hepatology 2002;35:1010-21.

12 Rosmorduc O, Wendum D, Corpechot C, et al. Hepatocellular hypoxia-induced vascular endothelial growth factor expression and angiogenesis in experimental biliary cirrhosis. Am J Pathol 1999:155:1065-73.

13 Wang YQ, Ikeda K, Ikebe T, et al. Inhibition of hepatic stellate cell proliferation and activation by the semisynthetic analogue of fumagillin TNP-470 in rats. Hepatology 2000;32:980-9.

14 Yancopoulos GD, Davis S, Gale NW, et al. Vascular-specific growth factors and blood vessel formation. Nature 2000;407:242-8.

15 Shibuya M. Structure and function of VEGF/VEGF-receptor system involved in angiogenesis. Cell Struct Funct 2001:26:25-35.

16 Karkkainen MJ, Petrova TV. Vascular endothelial growth factor receptors in the regulation of angiogenesis and lymphangiogenesis. Oncogene 2000; 19:5598-605

17 Gerber HP, Hillan KJ, Ryan AM, et al. VEGF is required for growth and survival in neonatal mice. Development 1999;1 26:1149-59.

18 Bruns CJ, Liu W, Davis DW, et al. Vascular endothelial growth factor is an in vivo survival factor for tumor endothelium in a murine model of colorectal carcinoma liver metastases. Cancer 2000:89:488-99.

19 Alon T, Hemo I, Itin A, et al. Vascular endothelial growth factor acts as a survival factor for newly formed retinal vessels and has implications for retinopathy of prematurity. Nat Med 1995;1:1024-8

20 Torimura T, Ueno T, Kin M, et al. VEGF participates in neovascularization and sinusoidal capillarization in HCC. Cells Hepatic Sinusoid 1999:7:300-301

21 Mashiba S, Mochida S, Ishikawa K, et al. Inhibition of hepatic stellate cell contraction during activation in vitro by vascular endothelial growth factor in association with upregulation of FLT tyrosine kinase receptor family, FLT-1. Biochem Biophys Res Commun 1999;258:674-8.

22 Ishikawa K, Mochida S, Mashiba S, et al. Expressions of vascular endothelial growth factor in nonparenchymal as well as parenchymal cells in rat liver after necrosis. Biochem Biophys Res Commun 1999:254:587-93.

23 Ankoma-Sey V, Wang Y, Dai Z. Hypoxic stimulation of vascular endothelial growth factor expression in activated rat hepatic stellate cells. Hepatology 2000;31:141-8.

24 Ankoma-Sey V, Matli M, Chang KB, et al. Coordinated induction of VEGF receptors in mesenchymal cell types during rat hepatic wound healing. Oncogene 1998;17:115-21.

25 Shibuya $M$. Structure and dual function of vascular endothelial growth factor receptor-1 (Flt-1). Int J Biochem Cell Biol 2001:33:409-20.

26 Kroll J, Waltenberger J. The vascular endothelial growth factor receptor KDR activates multiple signal transduction pathways in porcine aortic endothelial cells. J Biol Chem 1997;272:32521-7.

27 Shibuya $M$. Role of VEGF-flt receptor system in normal and tumor angiogenesis. Adv Cancer Res 1995; 67:281-316.

28 Waltenberger J, Claesson-Welsh L, Siegbahn A, et al. Different signal transduction properties of KDR and Flt 1 , two receptors for vascular endothelial growth factor. J Biol Chem 1994;269:26988-95.

29 Ferrara N. Vascular endothelial growth factor: molecular and biological aspects. Curr Top Microbiol Immunol 1999;237:1-30.

30 Adini A, Kornaga T, Firoozbakht F, et al. Placental growth factor is a survival factor for tumor endothelial cells and macrophages. Cancer Res 2002:62:2749-52.

31 Lyden D, Hattori K, Dias S, et al. Impaired recruitment of bone-marrow-derived endothelial and hematopoietic precursor cells blocks tumor angiogenesis and growth. Nat Med 2001;7:1 194-201.

32 Hiratsuka S, Maru Y, Okada A, et al. Involvement of Flt-1 tyrosine kinase (vascular endothelial growth factor receptor-1) in pathological angiogenesis. Cancer Res 2001;61:1207-13.
33 Hattori K, Heissig B, Wu Y, et al. Placental growth factor reconstitutes hematopoiesis by recruiting VEGFR 1 (+) stem cells from bone-marrow microenvironment. Nat Med 2002:8:841-9.

34 Luttun A, Tjwa M, Moons L, et al. Revascularization of ischemic tissues by PIGF treatment, and inhibition of tumor angiogenesis, arthritis and atherosclerosis by anti-Flt1. Nat Med 2002;8:831-40.

35 Yoshiji H, Kuriyama S, Hicklin DJ, et al. KDR/Flk- 1 is a major regulator of vascular endothelial growth factor-induced tumor development and angiogenesis in murine hepatocellular carcinoma cells. Hepatology 1999:30:1179-86.

36 Yoshiji H, Kuriyama S, Hicklin DJ, et al. The vascular endothelial growth factor receptor KDR/Flk- 1 is a major regulator of malignant ascites formation in the mouse hepatocellular carcinoma model. Hepatology 2001;33:841-7.

37 Prewett $M$, Huber J, Li $Y$, et al. Antivascular endothelial growth factor receptor (fetal liver kinase 1) monoclonal antibody inhibits tumor angiogenesis and growth of several mouse and human tumors. Cancer Res 1999;59:5209-18.

38 Yoshiji H, Kuriyama S, Yoshii J, et al. Angiotensin-ll type 1 receptor interaction is a major regulator for liver fibrosis development in rats. Hepatology 2001;34:745-50.

39 Yoshiii H, Yoshii J, lkenaka Y, et al. Inhibition of renin-angiotensin system attenuates liver enzyme-altered preneoplastic lesions and fibrosis development in rats. J Hepatol 2002;37:22-30.

40 Yoshiii H, Kuriyama S, Miyamoto Y, et al. Tissue inhibitor of metalloproteinases- 1 promotes liver fibrosis development in a transgenic mouse model. Hepatology 2000;32:1248-54.

41 Yoshiji H, Kuriyama S, Yoshii J, et al. Synergistic effect of basic fibroblast growth factor and vascular endothelial growth factor in murine hepatocellular carcinoma. Hepatology 2002;35:834-42.

42 Rockwell P, Neufeld G, Glassman A, et al. In vitro neutralization of vascular endothelial growth factor activation of flk-1 by a monoclonal antibody. Mol Cell Differ 1995;3:91-109.

43 Friedman SL, Roll FJ, Boyles J, et al. Maintenance of differentiated phenotype of cultured rat hepatic lipocytes by basement membrane matrix. J Biol Chem 1989:264:10756-62

44 Seetharam L, Gotoh N, Maru Y, et al. A unique signal transduction from FLT tyrosine kinase, a receptor for vascular endothelial growth factor VEGF. Oncogene 1995; 10:135-47.

45 Yamane A, Seetharam L, Yamaguchi S, et al. A new communication system between hepatocytes and sinusoidal endothelial cells in liver through vascular endothelial growth factor and Flt tyrosine kinase receptor family (Flt-1 and KDR/FIk-1). Oncogene 1994;9:2683-90.

46 Yoshiji H, Harris SR, Raso E, et al. Mammary carcinoma cells over-expressing tissue inhibitor of metalloproteinases- 1 show enhanced vascular endothelial growth factor expression. Int J Cancer 1998;75:81-7.

47 Nakatsukasa H, Evarts RP, Hsia CC, et al. Transforming growth factor-beta 1 and type I procollagen transcripts during regeneration and early fibrosis of rat liver. Lab Invest 1990;63:171-80.

48 Lindsay CK, Sinha CC, Thorgeirsson UP. Morphological study of vascular dissemination in a metastatic hepatocellular carcinoma model in the monkey. Hepatology 1997;26:1209-15.

49 Hellwig SM, Damen CA, van Adrichem NP, et al. Endothelial CD34 is suppressed in human malignancies: role of angiogenic factors. Cancer Lett 1997; 120:203-11.

50 Friedman SL, Arthur M. Activation of cultured rat hepatic lipocytes by Kupffer cell conditioned medium. Direct enhancement of matrix synthesis and stimulation of cell proliferation via induction of platelet-derived growth factor receptors. J Clin Invest 1989;84:1780-5.

51 Tada $\mathbf{H}$, Shiho O, Kuroshima K, et al. An improved colorimetric assay for interleukin 2. J Immunol Methods 1986:93:157-65.

52 Cui S, Hano H, Sakata A, et al. Enhanced CD34 expression of sinusoid-like vascular endothelial cells in hepatocellular carcinoma. Pathol Int 1996;46:751-6.

53 El-Assal ON, Yamanoi A, Soda Y, et al. Clinical significance of microvessel density and vascular endothelial growth factor expression in hepatocellular carcinoma and surrounding liver: possible involvement of vascular endothelial growth factor in the angiogenesis of cirrhotic liver. Hepatology 1998;27:1554-62

54 Arthur MJ, Mann DA, Iredale JP. Tissue inhibitors of metalloproteinases, hepatic stellate cells and liver fibrosis. J Gastroenterol Hepatol 1998;13(suppl):S33-8.

55 Suzuma K, Naruse K, Suzuma I, et al. Vascular endothelial growth factor induces expression of connective tissue growth factor via KDR, Flt] , and phosphatidylinositol 3- kinase-akt-dependent pathways in retinal vascular cells. J Biol Chem 2000;275:40725-31.

56 Jarnagin WR, Rockey DC, Koteliansky VE, et al. Expression of varian fibronectins in wound healing: cellular source and biological activity of the ElllA segment in rat hepatic fibrogenesis. J Cell Biol 1994;127/6 P 2):2037-48.

57 Maher JJ, McGuire RF. Extracellular matrix gene expression increases preferentially in rat lipocytes and sinusoidal endothelial cells during hepatic fibrosis in vivo. J Clin Invest 1990;86:1641-8

58 Roskams T, Moshage H, De Vos R, et al. Heparan sulfate proteoglycan expression in normal human liver. Hepatology 1995:21:950-8. 